\title{
Common Illnesses, Patient Physician Interactions, Continuity, and Practice Organization
}

\author{
Marjorie A. Bowman, MD, MPA, and Anne Victoria Neale, PhD, MPH
}

As our readership continues to expand dramatically, we are pleased to have an issue with broad range of articles all about common issues or illnesses seen daily, providing much information that will inform patient care and aid the practice of medicine. Included are articles addressing the effect of shared decision making about PSA testing and weight loss management, capitated payments to patient education, physician language related to adherence, and various factors of provider-patient continuity. We also have articles comparing outcomes of Cesarean sections by family physicians and obstetricians, articles about the natural history of symptoms (dangerous or otherwise) in childhood febrile illnesses, and articles providing a different look at sample medications, the evolving use of narcotics for chronic pain, a risk estimation score for male osteoporosis, a simple test for detecting cognitive impairment in people with low literacy, reproductive health care for adolescent women, and the overlap syndrome between asthma and chronic obstructive pulmonary disease. In addition, we note that scores on the American Board of Family Medicine certification examination vary substantially across the country and by various residency factors. (J Am Board Fam Med 2013;26:347-349.)

\section{Practice Organization and Management}

Pearson et $\mathrm{al}^{1}$ report that high-but not moderate-levels of capitation were associated with much higher rates of providing patient education, which can benefit patient outcomes. By looking at the factors associated with such continuity, Saultz et $\mathrm{al}^{2}$ provide valuable details extending typically expected results (such as the frequency of being in the office) to other specific results that could help offices improve their patient-provider continuity in the ambulatory care office setting. For example, the authors assess continuity by numbers of patients compared with session frequency, and the comparisons extend to associated mid-level providers.

Our interest in outcomes extends to the maternity care of women, and Johnson et $\mathrm{al}^{3}$ found similar outcomes in a comparison of 2 different rural hospitals respectively staffed for Cesarean sections by family physicians and obstetrics. While there are many factors that could account for this, particularly the limited sample size, this finding is still reassuring. Of course, it does seem that adequate

Conflict of interest: The authors are editors of the $7 A B F M$. training and ongoing experience should lead to similar outcomes.

From the Netherlands, Huibers et $\mathrm{al}^{4}$ followed up with patients who had spoken with an advice nurse by phone after office hours. Of interest for readers from the United States, the advice nurses had a physician in the call center about half of the time. In general, the telephone calls were not appreciated as much as home visits or in-office consultations after hours. About half of patients had follow-up visits, and although the calls were positively rated, those who did not have a follow-up visit were more likely to rate the telephone call highly.

Brown et $\mathrm{al}^{5}$ provide greater evidence on the lack of medical usefulness of medications typically found in sample closets. In their detailed analysis, a generic drug for the same indications as almost all the sample closet medications was available on the market; the authors also provide data on cost and specifics of medication usefulness. The average 1 -month cost for the sample medications is $\$ 178$ much higher than the cost of the generic alternatives.

Xierali et $\mathrm{al}^{6}$ found that almost three quarters of family physicians use electronic health records, and 
investigated factors associated with such use. Rurality was not relevant, but those with faculty status and those employed by an health maintenance organization were more likely to use electronic health records in their practice.

\section{Doctor-Patient Interactions}

Two articles in this issue look at changing practice patterns. According to Franklin, ${ }^{7}$ primary care providers in Washington State, where dosing guidelines were published in 2008, report decreasing use of narcotics for chronic noncancer pain. Nurse practitioners were less likely to know about the regulations and more likely to have stopped prescribing narcotics. The other article concerns testing for prostate-specific antigen (PSA). Much of the PSA testing in the United States is performed in men older than age 75 although the US Preventive Services Task Force ${ }^{8}$ in 2008 recommended against PSA testing for men older than 75. Li et $\mathrm{al}^{9}$ analyzed patient reports of doctor-patient conversations and PSA testing, and found that most discussions were associated with increased testing, thus not providing a clear path to decrease the rate of PSA "overtesting."

In the article by Keeley et al, ${ }^{10}$ physician time spent using certain motivational interviewing techniques and empathy improved patient uptake and adherence to antidepressants, suggesting that some forms of educational time with patients can be better than others. Ferrante et $\mathrm{al}^{11}$ identified patient preferences for the type of weight loss counseling preferred from their physicians and noted agreement between white and African American women. However, white women may first need assistance overcoming stigma, depression, and low self-esteem before attempting weigh loss.

\section{New Clinical Information and Reviews}

Two articles involve instruments for use in the office. Having a better, short, and easy instrument to screen for cognitive impairment in patients of low literacy is needed. Hamrick et $\mathrm{al}^{12}$ created and investigated just such an instrument, a Modified Mini-Mental State Examination, which takes out spelling and math from the Mini-Mental State Examination and puts in the relatively quick backward spelling of the days of the week-a terrific idea! Cass et $\mathrm{al}^{13}$ provide a prospective validation in the primary care setting of the Male Osteoporosis Risk
Estimation Score as a screening instrument to determine which men older than age 60 should receive screening to detect osteoporosis.

Hayon et $\mathrm{al}^{14}$ present a helpful and readable clinical review of reproductive care for adolescents. In another article, Nakawah et $\mathrm{al}^{15}$ review what is known about diagnosing asthma versus chronic obstructive pulmonary disease and the overlap between causes, manifestations, and treatment of the two.

Clinicians often consider parent-reported symptoms to suggest significant illness in children. However, in the study by Kool et $\mathrm{al}^{16}$ from the Netherlands, such symptoms reported by parents were not good predictors of significant illness in young children with fever. This article also provides some excellent data on the natural course of febrile illnesses.

Finally, in a fascinating study and a call for action, Falcone et $\mathrm{al}^{17}$ report publically available data on the average examination scores on the American Board of Family Medicine certification examination. They found that many US family medicine residency programs have low average examination scores and high failure rates among their graduates that do not meet the Accreditation Council for Graduate Medical Education recommendations. Furthermore, the variation in pass rates is substantial and varies by region and size of the residency. Much discussion should ensue.

\section{Next: Practice-based Research Theme Issue}

Our annual practice-based research theme issue will be published in September/October 2013. As usual, this will include a range of perspectives and important new research findings. Articles run the gamut from clinical care to primary care epidemiology to prevention and screening. We also have special communications about practice-based research networks. The deadline for submissions for consideration in the 2014 practice-based research theme issue will be January 17, 2014.

\section{Call for Papers: High Touch in an Electronic Age}

Twitter and Facebook may be as addictive as cigarettes, but our addiction to technology may mix both blessings and problems for health care. We are soliciting articles that explore the value, benefits, and problems of a range of technology-from 
electronic health records to home health tools to telemedicine-for the general health of patients and that are pertinent to primary health care. Are checklists and paperwork benefiting us and our patients, or are they increasing costs, devaluing the importance of the individual person's health, and creating morale problems for health care professionals? What solutions exist for maximizing value and high touch in an electronic age? Do we have to choose between Marcus Welby and health information technology?

The following topics are of high priority for this theme issue: Do medication errors increase or decrease with technology? Are there changes in conversations between doctor and patient with the use of technology? Does medication reconciliation reduce errors, increase errors, or take time away from other valuable aspects of the doctor-patient visit? How do older versus younger doctors adapt to electronic health records? What is the value and cost of electronic health records to small practices, particularly those whose physicians are older than age 50? Has the increased amount of documentation for each visit aided or inhibited good care? Do electronic automatic phrases and visit templates affect patient outcomes?

The deadline for consideration for this theme issue is September 16, 2013, at 11:59 PM Eastern standard time.

\section{References}

1. Pearson WS, King DE, Richards C. Capitated payments to primary care providers and the delivery of patient education. J Am Board Fam Med 2013;26: 350-55.

2. Mittelstaedt TS, Mori M, Lambert WE, Saultz JW. Provider-practice characteristics that promote interpersonal continuity. J Am Board Fam Med 2013;26: 356-65.

3. Homan FF, Olson AL, Johnson DJ. A comparison of Cesarean section outcomes for rural family physicians and obstetricians. J Am Board Fam Med 2013; 26:366-72.

4. Huibers L, Koetsenruijter J, Grol R, Giesen P, Wensing M. Follow-up after telephone consultations at out-of-hours primary care. J Am Board Fam Med 2013;26:373-79.
5. Evans KL, Brown SR, Smetana GW. Sample closet medications are neither novel nor useful. J Am Board Fam Med 2013;26:380-87.

6. Xierali IM, Phillips Jr. RL, Green LA, Bazemore AW, Puffer JC. Factors influencing family physician adoption of electronic health records (EHRs). J Am Board Fam Med 2013;26:388-93.

7. Franklin GM, Fulton-Kehoe D, Turner JA, Sullivan MD, Wickizer TM. Changes in opioid prescribing for chronic pain in Washington State. J Am Board Fam Med 2013;26:394-400.

8. U.S. Preventive Services Task Force. Screening for prostate cancer: U.S. Preventive Services Task Force recommendation statement. Ann Intern Med 2008; 149:185-91.

9. Li J, Berkowitz Z, Richards TB, Richardson LC. Shared decision making in prostate-specific antigen testing with men older than 70 years. J Am Board Fam Med 2013;26:401-8.

10. Kaplan JE, Keeley RD, Engel M, Emsermann C, Brody D. Aspects of patient and clinician language predict adherence to antidepressant medication. J Am Board Fam Med 2013;26:409-20.

11. Chugh M, Friedman AM, Clemow LP, Ferrante JM. Women weigh in: obese African American and white women's perspectives on physicians' roles in weight management. J Am Board Fam Med 2013; 26:421-28.

12. Hamrick I, Hafiz R, Cummings DM. Use of days of the week in a modified mini-mental state exam (MMMSE) for detecting geriatric cognitive impairment. J Am Board Fam Med 2013;26:429-35.

13. Cass AR, Shepherd AJ. Validation of the male osteoporosis risk estimation score (MORES) in a primary care setting. J Am Board Fam Med 2013;26: 436-44.

14. Hayon R, Dalby J, Paddock E, Combs M, Schrager S. Reproductive health care for adolescent women. J Am Board Fam Med 2013;26:460-69.

15. Obadah Nakawah M, Hawkins C, Barbandi F. Asthma, chronic obstructive pulmonary disease (COPD), and the overlap syndrome. J Am Board Fam Med 2013;26:470-77.

16. Kool M, Elshout G, Moll HA, Koes BW, van der Wouden JC, Berger MY. Duration of fever and course of symptoms in young febrile children presenting with uncomplicated illness. J Am Board Fam Med 2013;26:445-52.

17. Falcone JL, Middleton DB. Pass rates on the American Board of Family Medicine certification exam by residency location and size. J Am Board Fam Med 2013;26:453-59. 